\title{
NERIS Platform - An attempt to enhance European response to and recovery from radiological emergencies
}

\author{
R. MUSTONEN
}

\begin{abstract}
The European Platform on Preparedness for Nuclear and Radiological Emergency Response and Recovery (NERIS Platform) was established in June 15, 2010. The Mission of NERIS is to promote the involvement of different stakeholders and improve public confidence in capabilities of the key players in management of nuclear and radiological emergencies in Europe. The NERIS Platform encourages European, national, regional and local authorities, technical support organisations (TSOs), operators, professional organisations, research institutes, universities, non-governmental organisations (NGOs), and national and local stakeholders to co-operate in emergency management, and to facilitate access to expertise and technology in maintaining competence in the field of nuclear and radiological emergency management for the benefit of European countries and citizens. The vision is that by 2015, the self-sustaining NERIS association exists, and by 2020, all European organisations being members of the association are sharing common views and common approaches and are developing and using compatible technology and methods for consequence management of the emergencies. The NERIS Platform has, in September 2012, 43 member organisations representing stakeholders with a wide range of backgrounds, e.g. authorities, emergency centres, research organisations and the academic community. The Strategic Research Agenda (SRA), being under preparation, will provide the basis for priorities of future research and development in order to achieve the vision. The SRA therefore will communicate the future research needs, but will also be an instrument for creating synergies, co-operation and coordination internally between the NERIS participants and externally with activities taking place within other international forums.
\end{abstract}

Keywords: Nuclear/radiological emergencies/emergency management/European Platform

STUK, Radiation and Nuclear Safety Authority, P.O. Box 14, 00881 Helsinki, Finland. 


\section{Introduction}

After the Chernobyl accident in 1986, major progress has been made at the European, regional and national levels in management of response to and recovery from nuclear and radiological emergencies. Notwithstanding the broadly adequate provisions now in place in most countries and internationally, complacency should be forgotten and continuing vigilance remains important. Improvements, of a technical, organisational or political nature, are still needed in emergency management at the European level. The accident at the Fukushima 1 nuclear power plant in March 2011 in Japan proved that an event regarded as almost impossible was possible and a very small risk became reality. The Fukushima accident and the release of ${ }^{131} \mathrm{I}$ in autumn 2011 from one Hungarian institute producing radioisotopes demonstrated that closer co-operation and more effective and rapid data and information exchange between European emergency management organisations are needed. Nuclear and radiological safety and security have common goals and the systems and measures used to achieve these goals need to be complementary. Therefore, a well-coordinated approach in management of nuclear and radiological accidents and unauthorized acts is essential.

European organisations that participated in the European integrated research project EURANOS (Raskob et al., 2010) decided, at the end of the project, to create a unique European Platform on nuclear and radiological emergency response and recovery combining researchers, operational communities and relevant stakeholders (the NERIS Platform). In September 2012, 43 organisations have already joined the Platform. It comprises national and local authorities, technical support organisations, professional organisations, research institutes, universities and nongovernmental organisations.

The first General Assembly of the Platform was organised in June 2010 in Helsinki. Two working groups have been created so far. The first working group on "the practical implementation of the ICRP-103 (ICRP, 2007) recommendations" aims to understand the implications of these recommendations and how they can be adopted into national systems. The group will also develop guidance on how to adapt existing Decision Support Systems RODOS and ARGOS to the new approach. The objectives of the second working group on "processes and tools for emergency and rehabilitation preparedness at community level" are to exchange experience on local-national cooperation and stakeholder engagement in developing emergency and recovery strategies. The second General Assembly was held in May 2011 in Paris. The drafts for the vision and the Strategic Research Agenda (SRA) of the Platform were discussed.

\section{Mission and vision of the NERIS Platform}

The NERIS Platform is mission-oriented, focusing, not only on technological issues, but also on overall challenge in an emergency situation, including social-economic-legislative-implementational aspects. The mission of the NERIS Platform 
was discussed in the second General Assembly in May 2011. The mission and vision are written as;

The mission is to:

- built confidence among European citizens and decision-makers in capabilities of the key players and used methods in management of nuclear and radiological emergencies in Europe;

- encourage European, national, regional and local authorities, technical support organisations (TSOs), operators, professional organisations, research institutes, universities, non-governmental organisations (NGOs), and national and local stakeholders to co-operate to achieve the vision;

- facilitate access to expertise and technology and maintain competence in the field of management of nuclear and radiological emergencies for the benefit of European countries and citizens.

The vision is that by 2015 , the self-sustaining association for development of the joint European approach in responding to and recovering from nuclear and radiological emergencies exists, and by 2020, all European organisations being members of the association are sharing common views and common approaches and developing and using compatible technology and methods for consequence management of the emergencies.

To reach the vision the NERIS Platform has defined the following general objectives:

- improving the effectiveness of current European, national and local approaches for preparedness concerning nuclear or radiological emergency response and recovery;

- promoting more coherent approaches in preparedness for nuclear or radiological emergency response and recovery throughout Europe through the establishment of networking activities;

- maintaining and improving know-how and technical expertise in preparedness for nuclear or radiological emergency response and recovery among all interested stakeholders in Europe by developing a supranational training programme;

- identifying needs for further development and addressing new and emerging challenges in the field of preparedness for nuclear and radiological emergency response and recovery.

Membership of the Platform is open to all European organisations concerned with nuclear and radiological emergency response and recovery preparedness having expressed their interest in the activities of the Platform and having signed the Terms of Reference (www.eu-neris.net). 


\section{Ongoing activities of the NERIS Platform}

The NERIS Platform is operated by a Management Board that defines the work programme and a secretariat in charge of the technical administration of the Platform including the management of the NERIS website and the publication of two "NERIS Newsletters" per year. An R\&D Committee will elaborate the strategic orientation of the Platform based on the new areas of interest identified by the Working Groups and the expectations and demands of the Partners. The Platform members meet once a year on the occasion of the General Assembly.

The first General Assembly of the Platform was organised in June 2010 during the third European IRPA Congress in Helsinki to launch the NERIS Platform activities. The second General Assembly took place in May 2011 in Paris to review the initial results of the Platform's activities, elect new members to the Management Board and to discuss the long-term future of the Platform. Following the first NERIS General Assembly, the two working groups mentioned above were created.

New Working Groups on specific topics could be created in the future should there be sufficient interest.

The first working group on "the practical implementation of the ICRP recommendations" aims to explore the implications of these recommendations (ICRP, 2007; ICRP, 2009a; ICRP, 2009b) and how they can be adopted into national regulations. The group will also develop guidance on how to adapt existing Decision Support Systems to the new approach proposed by ICRP. The first meeting of this Working Group took place in November 2010 in France. 21 participants from 15 different countries discussed how the ICRP Publications 103, 109 and 111 could be implemented into national emergency management procedures and regulations. It was concluded that, in most European countries, the implementation has not started, although first attempts have been made to investigate the consequences to national regulations. The group also agreed on modifications that might be required to computer programs to simulate (a) all exposure pathways for the calculation of the residual dose in a given time period and (b) the impact of early and late phase countermeasures. It was agreed that the dose from consumption of contaminated food might be estimated in a simplistic way because restrictions on the use of contaminated food may be applied following a nuclear accident. It was recognised that the simulation tools should also contain a component to define and evaluate various scenarios to support emergency preparedness. In conclusion, the Working Group supported the idea of organising an international workshop in February 2012 on "the practical implementation of the ICRP recommendations". The Workshop provided a forum for discussion and sharing of experiences on the implementation of ICRP recommendations and for exploring the methodological and computational aspects related to the practical introduction of the new recommendations in existing decision support tools used in European Countries.

The objective of the second Working Group on "processes and tools for emergency and rehabilitation preparedness at community level" is to exchange experiences on local-national cooperation and stakeholder engagement in developing 
emergency and recovery strategies. The Group also aims to adapt or develop userfriendly processes and tools to assist communities in preparing for local cooperation, to test them in national or international exercises and to organize seminars on lessons learnt. The first meeting of the Working Group took place on November 2010 in France. 26 participants from 13 different countries discussed existing preparedness experiences with local communities in their respective countries as well as the topics of interest for these local communities in the future (e.g. management of water resources, agricultural and industrial areas, information and communication strategies). These experiences were presented through 3 phases: crisis management, end of the emergency and the transition phase; and the long-term. It included for example the presentation of a Nordic workshop (FOOD) on late phase countermeasures and safe food production in nuclear and radiological emergencies organised by NRPA in Norway, the French CODIRPA experience, led by the French Nuclear Safety Authority (ASN), that addresses the post-accident phase management issues, and workshops and training courses organised by VUJE Inc. with stakeholders in the Slovak Republic. Notably, it was agreed to design a template to collect information on the different initiatives, experiences and tools in a standardised format. Concerning the next Working Group meetings, specific topics will be addressed to further discuss the issues at stake at the community level.

The NERIS Platform also supports the organisation of training courses. The latest and next editions of these courses were scheduled as follows:

- The training course on "Preparedness and Response for Nuclear or Radiological Emergencies" organised by SCK $• \mathrm{CEN}$, took place on 17-21 October, 2011 in Mol, Belgium. The main objective of the course was to provide a comprehensive overview of the theoretical background and the practical aspects of nuclear and radiological emergency management. The target audience included all actors involved in emergency planning and response, from technical and radiological advisors to staff responsible for the overall emergency organisation and policy, such as civil protection and environmental protection officers. In 2011, two special sessions were added to the basic lectures. These were dedicated to the Fukushima accident and to communication in nuclear/ radiological emergencies. The course lectures were given by experts with international recognition in the field.

- The training course on "Preparedness for Nuclear and Radiological Post-Accident Rehabilitation" organised by CEPN, is planned to take place in 2013 in Fontenay-aux-Roses, France. This training course focuses on the post-accidental period, i.e. weeks, months and years that follow a nuclear accident or a radiological event. The main objective of the course is to provide principles and practical advice for those involved in the preparedness for rehabilitation of living conditions in contaminated areas. The course will offer a comprehensive overview of the various dimensions and challenges of rehabilitation, and also practical elements for the implementation of countermeasures for managing long-term contaminated rural and urban environment. A particular attention will be given to "stakeholder involvement" approaches to initiate preparedness 
processes and also to favour the redeployment of social and economic activities in the affected areas in case of an accident.

In the context of the 7th Euratom Research Framework Programme (Euratom, 2009), a research project has been launched in February 2011. The project "Towards a self sustaining European Technology Platform (NERIS-TP) on Preparedness for Nuclear and Radiological Emergency Response and Recovery" (http:// resy5.fzk.de/NERIS-TP/) is a three-year research project involving 19 organisations from 13 countries. NERIS-TP is co-ordinated by the Karlsruhe Institute of Technology (KIT). The working program reflects the two objectives of the project: firstly to solve urgent research needs such as the implementation of the new ICRP recommendations in the simulation models, the coupling of decision support systems such as ARGOS and RODOS to early notification systems and to carry out research activities to improve emergency management on the local and the national level; and secondly to establish the NERIS Platform as a sustainable platform on emergency response and recovery preparedness within the project duration of three years.

\section{The way forward}

The process for establishing technology platforms was suggested by the European Commission in 2003 (Commission of the European Communities, 2003). The Communication includes e.g.: "Sector-specific issues should be taken into account, including through setting specific objectives and milestones in some areas such as information and communication technologies. Increased coherence and co-ordination is needed at the level of the various stakeholders involved in the development and deployment of key technologies in Europe. This can be promoted by European technology platforms, bringing together the main stakeholders concerned, in order to set a common strategic agenda addressing research as well as, where appropriate, regulatory and standardisation issues".

This initiative was discussed at the end meeting of the large EURANOS project of the 6th Euratom Framework Programme in 24-26 June 2009. In 2009 the Commission launched a call for establishing a European platform on emergency and post-accident preparedness and management in the Euratom research programme for 2010 (Euratom, 2009). A European consortium responded to this call by sending a proposal to start the three-year NERIS-TP project mentioned above.

The process for establishing NERIS Platform will continue by writing a Strategic Research Agenda (SRA) in this field, and a Deployment Plan (DP) on how to implement the Strategic Research Agenda. The SRA will be a description of the main deficiencies in the present knowledge and the major challenges both in short and long term perspectives. When developing the SRA, the input and comments from all interested stakeholders will be essential to ensure the future activities comply with the vision. The work has to be a joint effort of the participating partners and the European Commission. Aim is that the SRA could be approved in the third General Assembly in May 2012 in Glasgow. 
The Management Board is preparing a statute for the NERIS Platform. Intention is that the platform would be a self sustaining association after the three-year period of the NERIS-TP project. A statute is necessary to get the platform as a legal entity. During the duration of the NERIS-TP project, the running costs of the platform are covered by the project, but after expiry of the project, the platform has to have its own funds to be able to cover necessary expenses. It means that some kind of membership fee will be necessary. Being a legal entity, the platform can charge a membership fee and also participate, as a partner, in public undertakings. Aim is to register the NERIS association under the French legislation and to present the statute in the third General Assembly in May 2012.

\section{REFERENCES}

Commission of the European Communities (2003) Communication from the Commission - investing in research: an action plan for Europe, $\operatorname{COM}(2003)$ 226.

Euratom (2009) Call for proposals under the 7th Euratom Framework Programme for Nuclear Research and Training Activities, 2009/C 284/09, Official Journal of the European Union, C 284.

ICRP Publication 103 (2007) The 2007 Recommendations of the International Commission on Radiological Protection, Ann. ICRP 37 (2-4).

ICRP Publication 109 (2009a) Application of the Commission's Recommendations for the Protection of People in Emergency Exposure Situations, Ann. ICRP 39 (1).

ICRP Publication 111 (2009b) Application of the Commission's Recommendations to the Protection of People Living in Long-term Contaminated Areas after a Nuclear Accident or a Radiation Emergency, Ann. ICRP 39 (3).

Raskob W., Gering F., Lochard J., Nisbet A., Starostova V., Tomic B. (2010) Overview and main achievements of the EURANOS project: European approach to nuclear and radiological emergency management and rehabilitation strategies. In: Enhancing Nuclear and Radiological Emergency Management and Rehabilitation, Key Results of the EURANOS European Project, W. Raskob, M. Hugon (eds.), Radioprotection 45 (5), S9-S22. 